\title{
Efficacy of ketamine in the rapid treatment of major depressive disorder: a meta-analysis of randomized, double-blind, placebo-controlled studies
}

This article was published in the following Dove Press journal:

Neuropsychiatric Disease and Treatment

3 November 2016

Number of times this article has been viewed

\author{
Yu Han ${ }^{1-3}$ \\ Jianjun Chen $2-4$ \\ Dezhi Zou ${ }^{1-3}$ \\ Peng Zheng ${ }^{1-3}$ \\ Qi $\mathrm{Li}^{1-3}$ \\ Haiyang Wang ${ }^{1-3}$ \\ Pengfei $\mathrm{Li}^{1-3}$ \\ Xinyu Zhou ${ }^{1-3}$ \\ Yuqing Zhang ${ }^{1-3}$ \\ Yiyun Liu't-3 \\ Peng $\mathrm{Xie}^{1-3}$ \\ 'Department of Neurology, The First \\ Affiliated Hospital of Chongqing \\ Medical University, ${ }^{2}$ Institute of \\ Neuroscience and the Collaborative \\ Innovation Center for Brain Science, \\ ${ }^{3}$ Chongqing Key Laboratory of \\ Neurobiology, ${ }^{4}$ Institute of Life \\ Sciences, Chongqing Medical \\ University, Chongqing, People's \\ Republic of China
}

Background: An increasing number of studies are reporting that ketamine could be treated as a novel antidepressant for major depressive disorder (MDD). Therefore, we performed this meta-analysis to comprehensively and systematically assess the efficacy of ketamine for treating patients with MDD.

Method: Randomized, double-blind, placebo-controlled studies on ketamine versus placebo for treating MDD were searched up to April 2016 in medical databases (PubMed, CCTR, Web of Science, Embase, CBM-disc, and CNKI). Three treatment time points (24 and $72 \mathrm{~h}$, and day 7 ) were chosen. Response and remission rates were the main outcomes. The random effects model was used. An intention-to-treat analysis was conducted.

Results: Nine high-quality studies that included 368 patients were selected to compare the efficacy of ketamine to placebo. The therapeutic effects of ketamine at 24 and $72 \mathrm{~h}$, and day 7 were found to be significantly better than placebo. Response and remission rates in the ketamine group at 24 and $72 \mathrm{~h}$, and day 7 were $52.2 \%$ and $20.6 \% ; 47.9 \%$ and $23.8 \%$; and $39.8 \%$ and $26.2 \%$, respectively. No significant heterogeneity existed, and the Egger's test showed no publication bias.

Conclusion: These results indicated that ketamine could yield a good efficacy in the rapid treatment of MDD. Future large-scale clinical studies are needed to confirm our results and investigate the mid- and long-term efficacy of ketamine in treating MDD.

Keywords: major depressive disorder, MDD, ketamine, meta-analysis

\section{Introduction}

Major depressive disorder (MDD) is a common psychiatric disorder in clinical practice, which is associated with enormous public health costs and morbidity. ${ }^{1,2}$ The clinical characteristics of MDD include low self-esteem, loss of interest in previously interesting activities, and changes in appetite. ${ }^{3}$ By 2020, MDD is estimated to become the second largest cause of disability. However, there are still no objective laboratory tests to help clinicians in the diagnosis of MDD, although many studies have been done to develop these tests. ${ }^{4-6}$ Our group has conducted many studies for identifying potential biomarkers for MDD diagnosis using metabolomics, ${ }^{7-9}$ which is used to identify novel biomarkers for various disease states. ${ }^{10-12}$ Another dilemma about the prevention and treatment of MDD is that no existing antidepressants could treat MDD patients with 100\% response rate. Nowadays, worldwide, about 33\% MDD patients do not respond to the existing antidepressants. ${ }^{13}$ Therefore, many novel treatments have been developed to treat MDD, such as electroconvulsive therapy and transcranial magnetic stimulation. ${ }^{14-17}$

\footnotetext{
Correspondence: Peng Xie

Department of Neurology, The First Affiliated Hospital of Chongqing Medical University, I Yixueyuan Road, Yuzhong District, Chongqing 400016, People's

Republic of China

Tel +862368485490

Fax +8623684851 II

Email xiepeng@cqmu.edu.cn
} 
Currently, due to the rapid action of ketamine in treating MDD, it has obtained great interest. Ketamine is a medication mainly used for starting and maintaining anesthesia, but recently, new insights have been gained into its potential antidepressive effects. As an $N$-methyl-D-aspartate receptor antagonist, effects of ketamine on mood disorders have been studied in many clinical studies. ${ }^{18,19}$ A systematic review reported that ketamine might be used as a valid and intriguing antidepressant option for treatment-resistant depression (TRD). ${ }^{20}$ Another systematic review reported that a single infusion of ketamine could yield ultra-rapid efficacy for MDD. ${ }^{21}$ A meta-analysis published in 2015 found that ketamine has a rapid antidepressive action in unipolar disorder. ${ }^{22}$ But in this meta-analysis, databases were searched for articles published only up to December 2013 and only four studies were included. Recently, some high-quality randomized controlled trials (RCTs) on the treatment of MDD with ketamine have been published. ${ }^{23,24}$ Therefore, there is an urgent need for additional meta-analysis to aid clinicians in establishing an optimal treatment method.

\section{Methods}

\section{Study selection}

The first step of this meta-analysis was to identify eligible trials. Electronic searches were performed in international databases (PubMed, CCTR, Web of Science, and Embase), two Chinese databases (CBM-disc and CNKI), and relevant websites for articles published up to April 2016. The search terms used were "depress*" and "ketamine". In order to mitigate language bias, no language restriction was imposed. Reference documents listed in relevant papers, conference summaries, and the International Clinical Trials Registry Platform were also researched.

We selected studies for subsequent analysis according to the following inclusion criteria: i) randomized, double-blind, placebo-controlled studies comparing ketamine and placebo (active or not); ii) MDD patients aged >18 years; iii) provided informed consent; and iv) mood assessed by Hamilton Depression Rating Scale (HDRS), Montgomery-Åsberg Depression Rating Scale (MADRS), or Clinical Global Impression (CGI). Meanwhile, studies were excluded based on the following criteria: i) no control group; ii) patients with "narrow" or secondary depression diagnoses (eg, postpartum depression and vascular depression); iii) case reports and reviews; and iv) duplicate studies.

\section{Outcome measures}

Response rate was chosen as a primary outcome, being the most consistently reported estimates of acute treatment efficacy. ${ }^{25,26}$ Remission rate was also analyzed, as it was arguably more clinically relevant than response rate. ${ }^{27,28} \mathrm{We}$ defined response as at least a 50\% reduction in the absolute HDRS or MADRS score from baseline, or significant improvement in the CGI, at the conclusion of therapy. ${ }^{28,29}$ When trials reported results from all three rating scales, HDRS was preferentially selected. Three treatment time points were chosen ( 24 and $72 \mathrm{~h}$, and day 7 ) to assess the rapid antidepressive effect of ketamine.

\section{Data extraction}

Two reviewers extracted data independently using the aforementioned inclusion and exclusion criteria. For data that could not be directly retrieved, additional information was retrieved through correspondence with the primary author. Any disagreement was resolved by consensus and, if needed, a third reviewer was consulted. Data retrieved from the RCTs included the first author, the year of publication, country of origin, study design, participant characteristics, therapy period, and outcomes (response and remission rates).

\section{Statistical analysis}

The summary odds ratio (OR) and 95\% confidence interval (CI) were used as the effect parameters for this meta-analysis. Heterogeneity was assessed using the chisquare test $(P \leq 0.10)$ and $I$ squared index $\left(I^{2}>50 \%\right) .{ }^{30}$ The Mantel-Haenszel random effects model was chosen, as it was assumed that the included studies probably had varying true treatment effects. ${ }^{31}$ The weighting of each study was mainly performed according to the number of patients in each included trials. To perform a clinically sound analysis, a worst-case scenario analysis of dropouts was used, under the assumption that all such patients did not respond to treatment. ${ }^{26}$ The potential presence of publication bias could not be accurately assessed using the funnel plot because $<10$ studies were included; then Egger's test was conducted. ${ }^{32}$ The protocol of the systemic review followed the recommendations for conducting a meta-analysis. We used RevMan5 software (Cochrane Information Management System) to perform meta-analysis. All tests here about outcomes were two-sided, with statistical significance set to $P<0.05$.

\section{Results}

\section{Literature search}

The initial Internet search yielded 169 potentially relevant studies. After excluding duplicates, 157 studies remained. Among these studies, 142 studies were excluded by reviewing the titles and abstracts. Among the remaining 15 studies, 


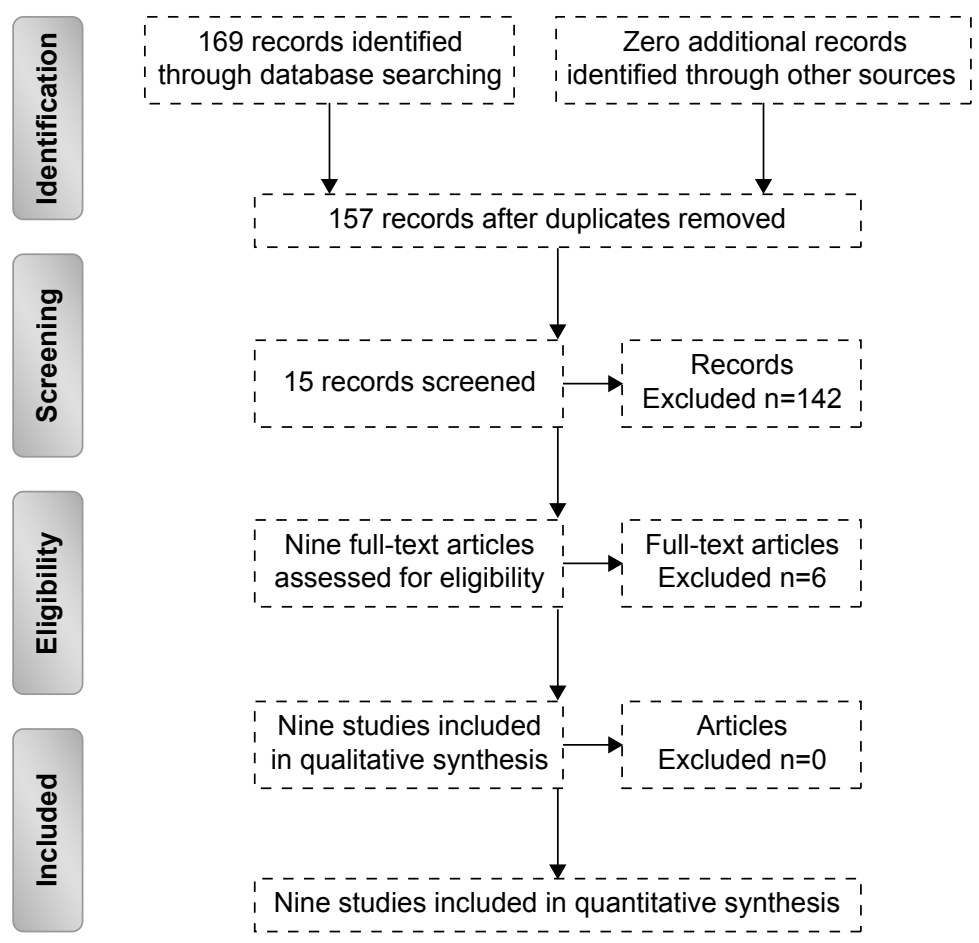

Figure I PRISMA flow diagram.

Abbreviation: PRISMA, preferred reporting items for systematic reviews and meta-analyses.

six were excluded after two reviewers independently examined the full texts due to the following reasons: no control group; part of the recruited patients had other psychiatry disorders; using ketamine first for all patients, and then assigning the patients to different groups to study other treatment methods. At last, nine studies met the aforementioned inclusion/exclusion criteria and were used to perform meta-analysis ${ }^{23,24,33-39}$ (Figure 1).

\section{Characteristics of included RCTs}

In this study, nine included studies $(100 \%)$ conducted allocation concealment, and the baseline characteristics were matched in all studies. Moreover, blinding was very difficult in the clinical trials, but all studies here blinded the outcome assessment. Therefore, all studies in this study were considered to be of consistently high quality. Totally, nine studies contained 368 adult patients with MDD. Part of included patients had various degrees of TRD. In the intervention group, patients from eight studies received $0.5 \mathrm{mg} / \mathrm{kg}$ ketamine through intravenous infusions, ${ }^{23,24,33-38}$ and patients from one study received $0.54 \mathrm{mg} / \mathrm{kg}$ ketamine. ${ }^{39}$ Six studies were from the US, ${ }^{23,33-37}$ one was from the Czech Republic, ${ }^{39}$ and two were from the People's Republic of China. ${ }^{24,38}$ Two studies used active placebo (electroconvulsive therapy and midazolam). ${ }^{34,36}$ The main characteristics of included RCTs are described in Tables 1 and 2 .

Table I Characteristics of patients in included studies

\begin{tabular}{|c|c|c|c|c|c|c|c|}
\hline Study & $F / M$ & Age (years) & Scale & Scale score & Response criteria & Remission criteria & TR \\
\hline Zarate et $\mathrm{a}^{35}$ & $12 / 6$ & $18-65$ & 21-item HDRS & $\geq 18$ & $>50 \%$ reduction & HDRS $\leq 7$ & Yes $^{a}$ \\
\hline Murrough et $\mathrm{al}^{34}$ & $37 / 35$ & $21-80$ & MADRS & NA & $>50 \%$ reduction & HDRS $\leq 7$ & Yes $^{\mathrm{a}}$ \\
\hline Berman et $\mathrm{al}^{33}$ & $5 / 4$ & $23-56$ & 25-item HDRS & NA & $>50 \%$ reduction & HDRS $\leq 7$ & No \\
\hline Lapidus et al ${ }^{17}$ & $10 / 10$ & $21-65$ & MADRS & NA & $>50 \%$ reduction & MADRS $\leq 10$ & Yes $^{\mathrm{b}}$ \\
\hline Ghasemi et $\mathrm{al}^{36}$ & $10 / 8$ & $18-75$ & 25-item HDRS & NA & $>50 \%$ reduction & HDRS $\leq 7$ & No \\
\hline Sos et $\mathrm{a}^{39}$ & $15 / 15$ & $18-65$ & MADRS & NA & $>50 \%$ reduction & MADRS $\leq 10$ & No \\
\hline Hu et $\mathrm{al}^{24}$ & $17 / 10$ & $18-60$ & I7-item HDRS & $\geq 24$ & $>50 \%$ reduction & MADRS $\leq 10$ & Yes $^{\mathrm{a}}$ \\
\hline Singh et $\mathrm{a}^{23}$ & $45 / 22$ & $18-64$ & MADRS & NA & $>50 \%$ reduction & MADRS $\leq 10$ & Yes \\
\hline $\mathrm{Hu}$ et $\mathrm{al}^{38}$ & $11 / 19$ & $18-65$ & 24-item HDRS & NA & $>50 \%$ reduction & HDRS $\leq 7$ & No \\
\hline
\end{tabular}

Notes: ${ }^{a}$ Failure to respond to at least two adequate antidepressant trials. ${ }^{b}$ Failure to respond to at least one adequate antidepressant trials.

Abbreviations: F, female; HDRS, Hamilton Depression Rating Scale; M, male; MADRS, Montgomery-Åsberg Depression Rating Scale; NA, not applicable; TR, treatmentresistant. 
Table 2 Characteristics of included controlled trials

\begin{tabular}{|c|c|c|c|c|c|c|c|}
\hline Study & Country & Pairs & Randomized & Allocation & Assess & Baseline & $\begin{array}{l}\text { Ketamine } \\
\text { (mg/kg) }\end{array}$ \\
\hline Zarate et $\mathrm{al}^{35}$ & US & Ketamine vs saline solution & Yes & Blind & Blind & Match & 0.5 \\
\hline Murrough et $\mathrm{al}^{34}$ & US & Ketamine vs midazolam & Yes & Blind & Blind & Match & 0.5 \\
\hline Berman et $\mathrm{al}^{33}$ & US & Ketamine vs saline solution & Yes & Blind & Blind & Match & 0.5 \\
\hline Lapidus et $\mathrm{al}^{37}$ & US & Ketamine vs saline solution & Yes & Blind & Blind & Match & 0.5 \\
\hline Ghasemi et $\mathrm{al}^{36}$ & US & Ketamine vs ECT & Yes & Blind & Blind & Match & 0.5 \\
\hline Sos et $\mathrm{al}^{39}$ & Czech & Ketamine vs saline solution & Yes & Blind & Blind & Match & 0.54 \\
\hline Hu et $\mathrm{al}^{24}$ & People's Republic of China & Ketamine vs saline solution & Yes & Blind & Blind & Match & 0.5 \\
\hline Singh et $\mathrm{al}^{23}$ & US & Ketamine vs saline solution & Yes & Blind & Blind & Match & 0.5 \\
\hline Hu et $\mathrm{al}^{38}$ & People's Republic of China & Ketamine vs saline solution & Yes & Blind & Blind & Match & 0.5 \\
\hline
\end{tabular}

Abbreviation: ECT, electroconvulsive therapy.

\section{Time point at $24 \mathrm{~h}$}

Response rate at this time point was available for eight RCTs (Figure 2A). Overall, 84 of 161 (52.2\%) and 11 of 140 patients $(7.8 \%)$ receiving ketamine and placebo, respectively, were classified as responders. The pooled OR was 10.09 (95\% CI: 4.96-20.52, $z=6.38, P<0.00001$ ), indicating a significantly higher efficacy of ketamine than placebo in achieving response 1 day after the treatment.
Heterogeneity was very low $\left(I^{2}=0 \%, P=0.57\right)$. Egger's test showed that the outcome was not significantly influenced by publication bias.

Remission rate at this time point was available for six RCTs (Figure 2B). Overall, 26 of 126 (20.6\%) and 3 of 105 patients $(2.8 \%)$ receiving ketamine and placebo, respectively, met the remission criteria. The pooled OR was 5.25 (95\% CI: $1.82-15.17, z=3.06, P=0.002)$, indicating a

A

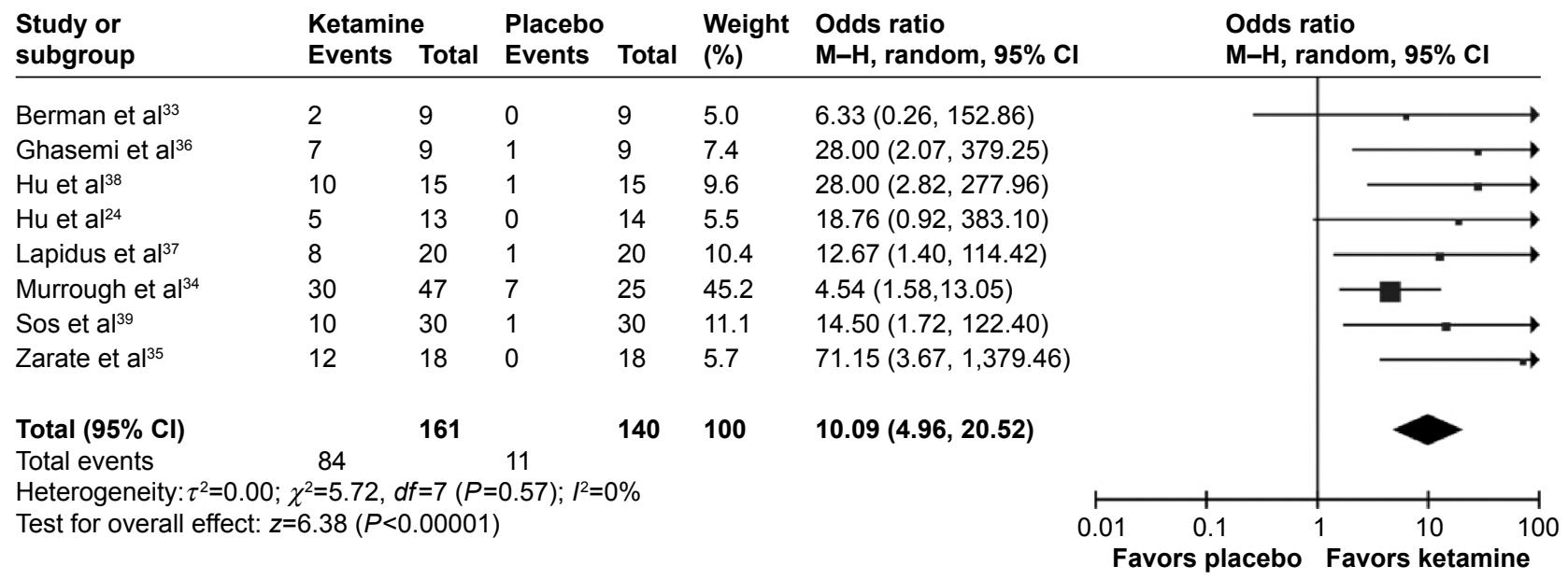

B

\begin{tabular}{|c|c|c|c|c|c|c|c|c|}
\hline $\begin{array}{l}\text { Study or } \\
\text { subgroup }\end{array}$ & $\begin{array}{l}\text { Ketamin } \\
\text { Events }\end{array}$ & Total & $\begin{array}{l}\text { Placebo } \\
\text { Events }\end{array}$ & Total & $\begin{array}{l}\text { Weight } \\
(\%)\end{array}$ & $\begin{array}{l}\text { Odds ratio } \\
\mathrm{M}-\mathrm{H} \text {, random, } 95 \% \mathrm{Cl}\end{array}$ & & $\begin{array}{l}\text { ratio } \\
\text { random, } 95 \% \mathrm{Cl}\end{array}$ \\
\hline Berman et $\mathrm{al}^{33}$ & 0 & 9 & 0 & 9 & & Not estimable & & \\
\hline Ghasemi et al ${ }^{36}$ & 1 & 9 & 0 & 9 & 10.1 & $3.35(0.12,93.83)$ & & \\
\hline Hu et $a^{24}$ & 1 & 13 & 0 & 14 & 10.4 & $3.48(0.13,93.30)$ & & \\
\hline Murrough et $a^{34}$ & 16 & 47 & 2 & 25 & 45.9 & $5.94(1.24,28.41)$ & & \\
\hline Sos et $\mathrm{al}^{39}$ & 3 & 30 & 1 & 30 & 20.9 & $3.22(0.32,32.89)$ & & \\
\hline Zarate et al ${ }^{35}$ & 5 & 18 & 0 & 18 & 12.7 & $15.07(0.77,296.44)$ & & \\
\hline Total (95\% Cl) & & 126 & & 105 & 100 & $5.25(1.82,15.17)$ & & \\
\hline Total events & 26 & & 3 & & & & & \\
\hline Heterogeneity: $\tau^{2}$ & $t^{2}=0.82, a$ & $f=4(P=$ & $=0.94) ; I^{2}=($ & & & & & \\
\hline Test for overall ef & $3.06(P=C$ & $.002)$ & & & & 0.01 & 0.1 & 10 \\
\hline
\end{tabular}

Figure 2 Meta-analysis of data at 24 h: (A) response rates, (B) remission rates. Abbreviation: $\mathrm{Cl}$, confidence interval. 
significantly higher efficacy of ketamine than placebo on achieving remission 1 day after the treatment. Heterogeneity was very low $\left(I^{2}=0 \%, P=0.94\right)$.

\section{Time point at $72 \mathrm{~h}$}

Response rate at this time point was available for nine RCTs (Figure 3A). Overall, 94 of 196 (47.9\%) and 23 of 172 patients (13.4\%) receiving ketamine and placebo, respectively, were classified as responders. The pooled OR was 7.42 (95\% CI: 3.97-13.88 $z=6.27, P<0.00001$ ), indicating a significantly higher efficacy of ketamine than placebo on achieving response 3 days after the treatment. Heterogeneity was very low $\left(I^{2}=0 \%, P=0.90\right)$. Egger's test showed that the outcome was not significantly influenced by publication bias.

Remission rate at this time point was available for six RCTs (Figure 3B). Overall, 30 of $126(23.8 \%)$ and 5 of 105 patients $(4.7 \%)$ receiving ketamine and placebo, respectively, met the remission criteria. The pooled OR was 4.04 (95\% CI: 1.66-9.85, $z=3.07, P=0.002)$, indicating a significantly higher efficacy of ketamine than placebo on achieving remission 3 days after the treatment. Heterogeneity was very low $\left(I^{2}=0 \%, P=0.88\right)$.

\section{Time point at day 7}

Response rate at this time point was available for nine RCTs (Figure 4A). Overall, 78 of 196 (39.8\%) and 23 of 172 patients (13.4\%) receiving ketamine and placebo, respectively, were classified as responders. The pooled OR was 5.66 (95\% CI: $2.92-10.97, z=5.13, P<0.00001$ ), indicating a significantly higher efficacy of ketamine than placebo in achieving response 7 days after the treatment. Heterogeneity was very low $\left(I^{2}=0 \%, P=0.90\right)$. Egger's test showed that the outcome was not significantly influenced by publication bias.

Remission rate at this time point was available for six RCTs (Figure 4B). Overall, 33 of $126(26.2 \%)$ and

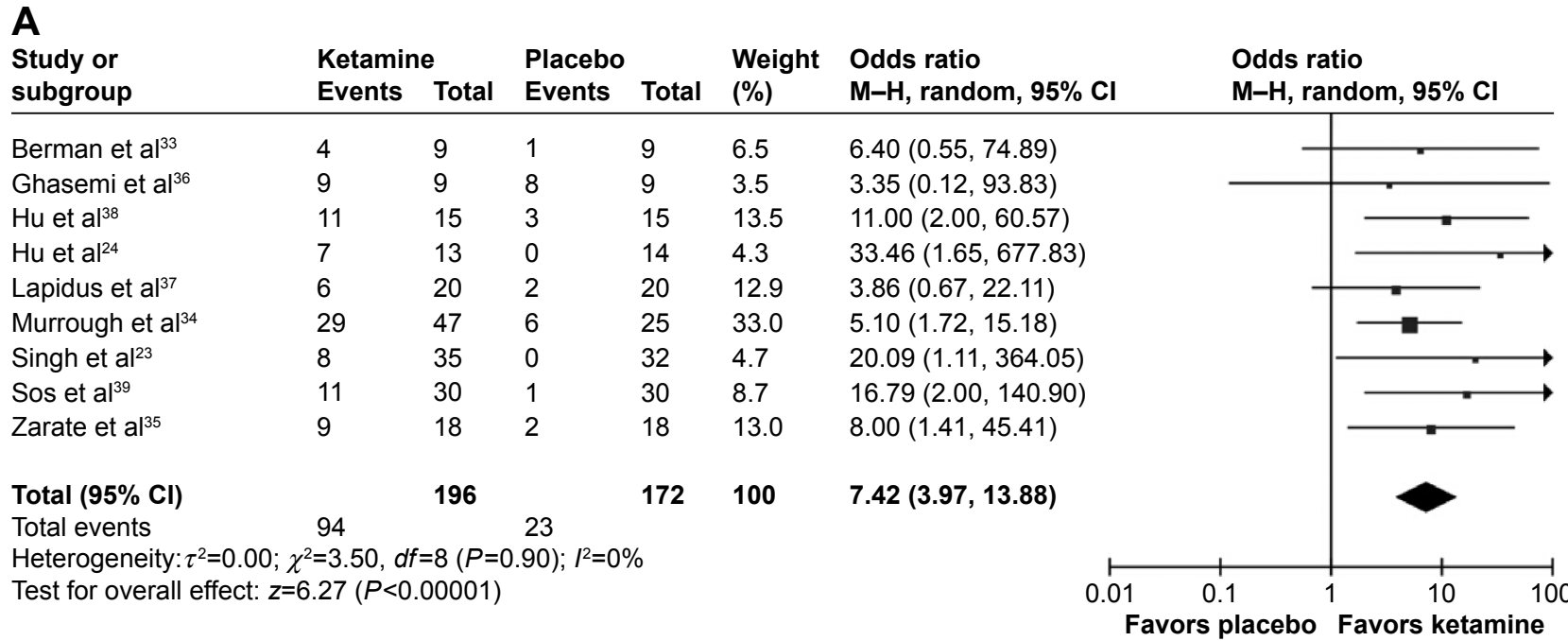

B

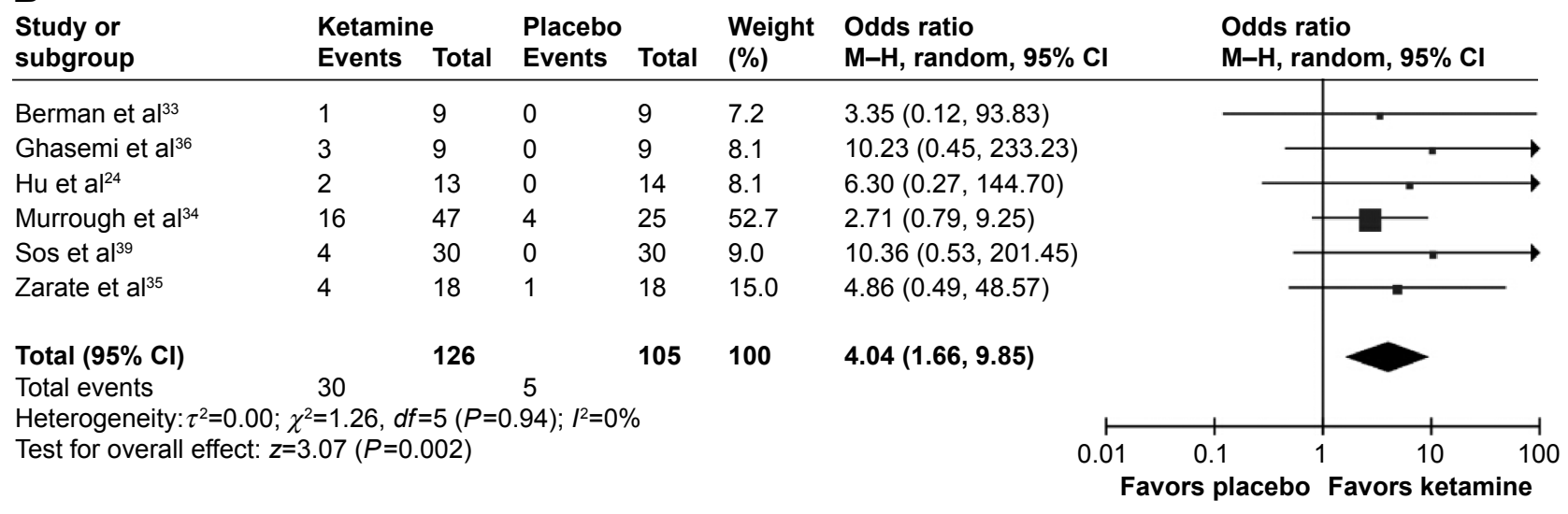

Figure 3 Meta-analysis of data at $72 \mathrm{~h}$ : (A) response rates, (B) remission rates. Abbreviation: $\mathrm{Cl}$, confidence interval. 


\section{A}

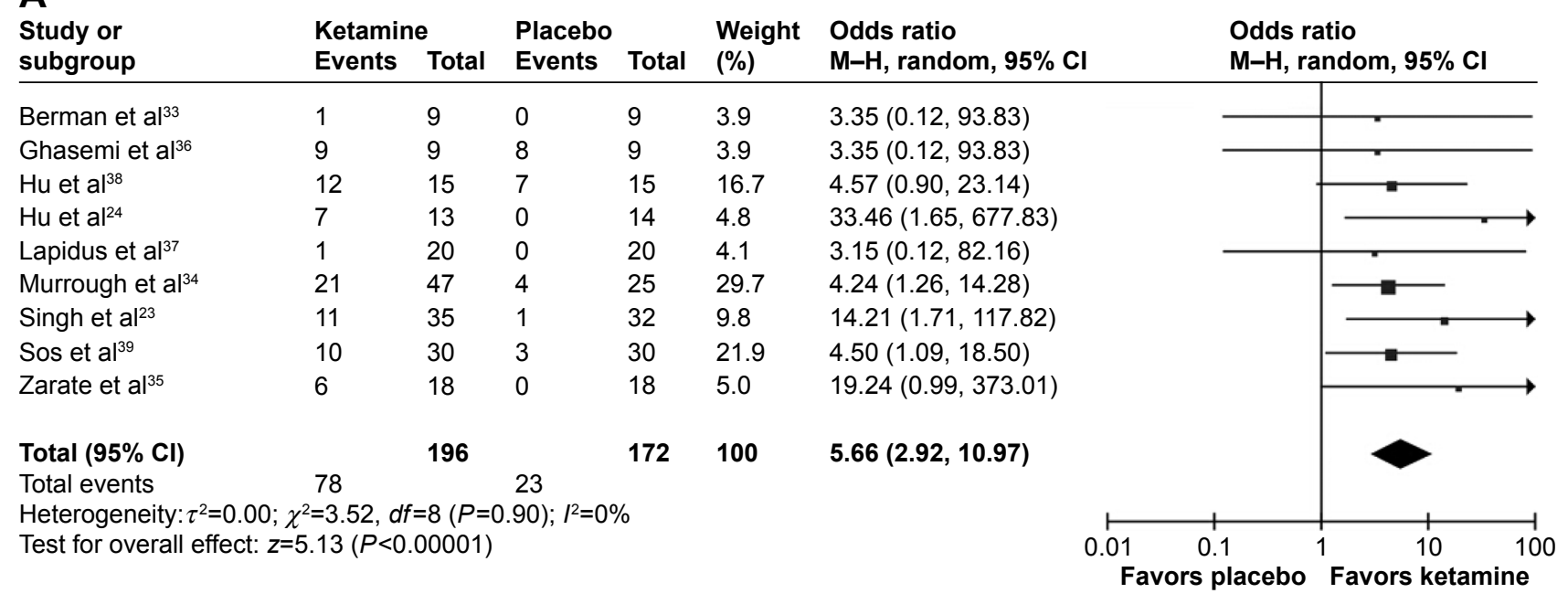

\section{B}

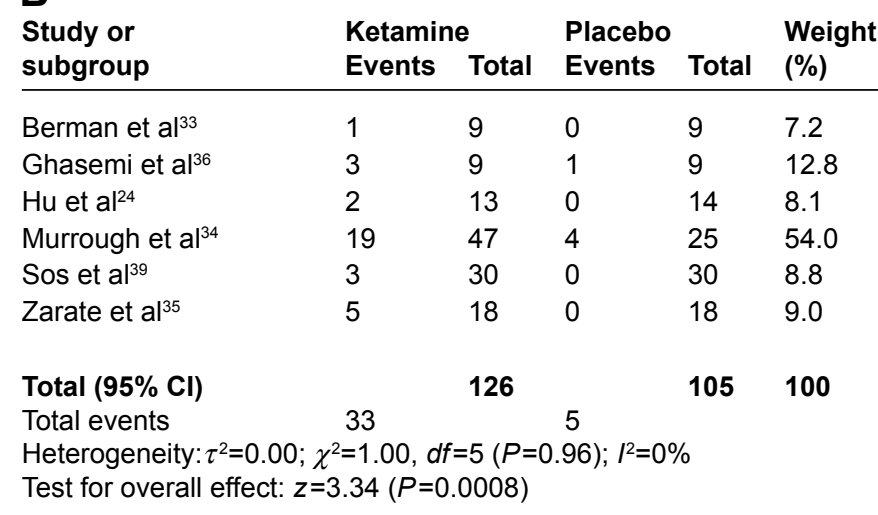

Figure 4 Meta-analysis of data at day 7: (A) response rates, (B) remission rates. Abbreviation: $\mathrm{Cl}$, confidence interval.

5 of 105 patients $(4.7 \%)$ receiving ketamine and placebo, respectively, met the remission criteria. The pooled OR was 4.60 (95\% CI: $1.88-11.26, z=3.34, P=0.0008)$, indicating a significantly higher efficacy of ketamine than placebo in achieving remission 7 days after the treatment. Heterogeneity was very low $\left(I^{2}=0 \%, P=0.96\right)$.

\section{Subgroup analysis}

Among the included studies, there were four crossover studies. Then, we conducted this subgroup analysis according to the type of included studies. The pooled analysis of the four crossover studies showed that the effect sizes on response rate were $16.21,7.19$, and 5.13 at 24 and $72 \mathrm{~h}$, and day 7 , respectively; the effect sizes on remission rate were $5.78,5.55$, and 7.74 at 24 and $72 \mathrm{~h}$, and day 7 , respectively. The pooled analysis of the other five studies showed that the effect sizes on response rate were 9.36, 7.59, and 5.96 at 24 and $72 \mathrm{~h}$, and day 7 , respectively; the effect sizes on remission rate were 5.00, 3.50, and 3.87 at 24 and $72 \mathrm{~h}$, and day 7 , respectively. These results were similar to the results from the meta-analysis of nine included studies.

\section{Discussion}

In this meta-analysis of nine randomized, double-blind, placebo-controlled studies of intravenous ketamine for MDD patients, we examined the rapid efficacy of ketamine by including more and newer high-quality studies than a previous meta-analysis. ${ }^{22}$ In the pooling analysis of these included studies, ketamine infusion was found to be significantly superior to placebo (active or not) in the acute treatment phase. The significantly higher response and remission rates started as early as day 1 , and lasted until days 3 and 7. The effect sizes on response rate were 10.09, 7.42, and 5.66 at 24 and $72 \mathrm{~h}$, and day 7 , respectively. The effect sizes on remission rate were 5.25, 4.04, and 4.60 at 24 and $72 \mathrm{~h}$, and day 7 , respectively. The response rates for current 
and widely prescribed antidepressants were different, which might have been caused by the different treatment times. These phenomena also indicated the usefulness of ketamine in the acute treatment of patients with MDD. Furthermore, all these findings were homogeneous throughout. Meanwhile, we found that the infusion of ketamine was well tolerated, because there were no serious adverse effects reported in the ketamine group. Additionally, as more than one-half of patients included in our meta-analysis had TRD, our study also indicated that ketamine might be a good choice in the acute treatment phase for TRD patients.

In our study, we have included almost all relevant randomized, double-blind, placebo-controlled studies. However, there might be some studies missing because they were published in journals that were not indexed by international databases. Fortunately, such studies are likely to be of low quality and would not significantly affect the conclusion of our review. ${ }^{40}$ Additionally, there were two studies that could not provide complete data. ${ }^{41,42}$ Despite our best efforts, such as sending email/fax to all authors and searching other related references, complete data were still not obtained. However, those two studies reported that ketamine was associated with a higher response rate. Therefore, the missing data of these two studies would not significantly affect the conclusion of this review.

A previous study reported that ketamine was associated with impairment of working, episodic, and procedural memory function, ${ }^{43}$ and long-term ketamine abuse could result in persistent neurocognitive impairments ${ }^{44}$ and even potential harmful brain changes. ${ }^{45}$ Although our study indicated that ketamine might have rapid antidepressant effects in patients with TRD, its impact on the neurocognitive function of patients with TRD has been assessed by only few studies to date. Murrough et al reported circumscribed memory impairment immediately following ketamine administration. ${ }^{46}$ But Shiroma et al investigated the neurocognitive effects of ketamine in patients with TRD and found no evidence of impairment. ${ }^{47}$ Moreover, a recent preclinical study has identified a ketamine metabolite that could act via an $N$-methyl-D-aspartate receptor-independent mechanism to produce rapid antidepressant-like effects, but without ketamine's side effects. ${ }^{48}$

Currently, the mechanism of ketamine in treating MDD is still unclear. A study reported that ketamine could induce the neuroplasticity-related processes to produce antidepressant efficacy. ${ }^{49} \mathrm{An}$ animal study reported that ketamine might represent the rapid neuroplastic modulator medications, which could lead to the increased synaptic signaling proteins and the increased number of new spine synapses in prefrontal cortex of rats. ${ }^{50}$ Hayley and Litteljohn suggested that ketamine could modify the connectivity of diverse cortical circuitry, which plays an important role in determining the key depressive symptoms. ${ }^{51}$ Also, it has been reported that ketamine could strengthen the appropriate emotional neural connections, and enhance the synaptogenesis in brain areas affected by the stress-related processes. ${ }^{20}$

\section{Limitations}

This study had some limitations. First, the number of included patients with MDD was relatively small. Second, the comparative efficacy of ketamine and placebo was assessed only in studies with treatment durations of 1-7 days. Thus, mid- and long-term antidepressant effects of ketamine could not be examined here. Third, we were not able to assess in our review whether repeated ketamine infusion could cause ketamine tolerance or not, and also the psychotomimetic side effects were not assessed. Finally, the dose of ketamine administered in eight of nine studies was $0.5 \mathrm{mg} / \mathrm{kg}$; however, the best dose of ketamine was not studied here.

In conclusion, by pooling analysis of nine randomized, double-blind, placebo-controlled studies, we found that ketamine was effective in the rapid treatment of MDD with a response rate of $39.8 \%-52.2 \%$ and a remission rate of $20.6 \%$ $26.2 \%$. Our meta-analysis provided powerful evidence that the effectiveness of ketamine was significantly better than placebo. While these results are very highly encouraging, several questions still need to be investigated in future largescale clinical studies about the mid- and long-term antidepressant effects, best dose, and ketamine tolerance.

\section{Acknowledgments}

This work was supported by the national key clinical specialist, the health bureau of Chongqing (No 20142008), the Natural Science Foundation Project of China (31271189, 81200899, 31300917, and 81401140), the National Basic Research Program of China (973 Program, grant no 2009CB918300), the Fund for Outstanding Young Scholars in Chongqing Medical University (CYYQ201502), and the Chongqing Science and Technology Commission (cstc2014jcyjA10102).

\section{Disclosure}

The authors report no conflicts of interest in this work.

\section{References}

1. Kessler RC, Chiu WT, Demler O, Merikangas KR, Walters EE. Prevalence, severity, and comorbidity of 12-month DSM-IV disorders in the National Comorbidity Survey replication. Arch Gen Psychiatry. 2005; 62(6):617-627. 
2. Collins PY, Patel V, Joestl SS, et al. Grand challenges in global mental health. Nature. 2011;475(7354):27-30.

3. Chen J, Zhou C, Liu Z, et al. Divergent urinary metabolic phenotypes between major depressive disorder and bipolar disorder identified by a combined GC-MS and NMR spectroscopic metabonomic approach. J Proteome Res. 2015;14(8):3382-3389.

4. Terhaar J, Viola FC, Bar KJ, Debener S. Heartbeat evoked potentials mirror altered body perception in depressed patients. Clin Neurophysiol. 2012;123(10):1950-1957.

5. Zheng $\mathrm{P}$, Zeng B, Zhou $\mathrm{C}$, et al. Altered gut microbiome induces depressive-like behaviors through a pathway mediated by the host's metabolism. Mol Psychiatry. 2016;21(6):786-796.

6. Ding X, Yang S, Li W, et al. The potential biomarker panels for identification of Major Depressive Disorder (MDD) patients with and without early life stress (ELS) by metabonomic analysis. PLoS One. 2014;9(5):e97479.

7. Zheng $\mathrm{P}$, Wang $\mathrm{Y}$, Chen $\mathrm{L}$, et al. Identification and validation of urinary metabolite biomarkers for major depressive disorder. Mol Cell Proteomics. 2013;12(1):207-214.

8. Zheng P, Chen J, Huang T, et al. A novel urinary metabolite signature for diagnosing major depressive disorder. J Proteome Res. 2013;12(12): $5904-5911$

9. Liu X, Zheng P, Zhao X, et al. Discovery and validation of plasma biomarkers for major depressive disorder classification based on liquid chromatography-mass spectrometry. J Proteome Res. 2015;14(5): 2322-2330.

10. Chen J, Liu Z, Fan S, et al. Combined application of NMR-and GCMS-based metabonomics yields a superior urinary biomarker panel for bipolar disorder. Sci Rep. 2014;4:5855.

11. Chen J, Huang H, Zhao L, et al. Sex-specific urinary biomarkers for diagnosing bipolar disorder. PloS One. 2014;9(12):e115221.

12. Qi Y, Li P, Zhang Y, et al. Urinary metabolite markers of precocious puberty. Mol Cell Proteomics. 2012;11(1):M111. 011072.

13. Schwartz J, Murrough JW, Iosifescu DV. Ketamine for treatmentresistant depression: recent developments and clinical applications. Evid Based Ment Health. 2016;19(2):35-38.

14. Chen J, Zhou C, Wu B, et al. Left versus right repetitive transcranial magnetic stimulation in treating major depression: a meta-analysis of randomised controlled trials. Psychiatry Res. 2013;210(3):1260-1264.

15. Chen J, Liu Z, Zhu D, et al. Bilateral vs. unilateral repetitive transcranial magnetic stimulation in treating major depression: a meta-analysis of randomized controlled trials. Psychiatry Res. 2014;219(1):51-57.

16. Xie J, Chen J, Wei Q. Repetitive transcranial magnetic stimulation versus electroconvulsive therapy for major depression: a meta-analysis of stimulus parameter effects. Neurol Res. 2013;35(10):1084-1091.

17. Kedzior KK, Gellersen HM, Roth Y, Zangen A. Acute reduction in anxiety after deep transcranial magnetic stimulation (DTMS) in unipolar major depression-a systematic review and meta-analysis. Psychiatry Res. 2015;230(3):971-974.

18. Sampath H, Sharma I, Dutta S. Treatment of suicidal depression with ketamine in rapid cycling bipolar disorder. Asia Pac Psychiatry. 2016;8(1):98-101.

19. Arunogiri S, Keks NA, Hope J. Should ketamine be used for the clinical treatment of depression? Australas Psychiatry. Epub 2016 Feb 5.

20. Serafini G, Howland RH, Rovedi F, Girardi P, Amore M. The role of ketamine in treatment-resistant depression: a systematic review. Curr Neuropharmacol. 2014;12(5):444.

21. Kishimoto T, Chawla JM, Hagi K, et al. Single-dose infusion ketamine and non-ketamine N-methyl-d-aspartate receptor antagonists for unipolar and bipolar depression: a meta-analysis of efficacy, safety and time trajectories. Psychol Med. 2016;46(7):1459.

22. Romeo B, Choucha W, Fossati P, Rotge JY. Meta-analysis of shortand mid-term efficacy of ketamine in unipolar and bipolar depression. Psychiatry Res. 2015;230(2):682-688.

23. Singh JB, Fedgchin M, Daly EJ, et al. A double-blind, randomized, placebo-controlled, dose-frequency study of intravenous ketamine in patients with treatment-resistant depression. Am J Psychiatry. 2016; 173(8):816-826
24. Hu YD, Xiang YT, Fang JX, et al. Single iv ketamine augmentation of newly initiated escitalopram for major depression: results from a randomized, placebo-controlled 4-week study. Psychol Med. 2016; 46(03):623-635.

25. Rush AJ, Kraemer HC, Sackeim HA, et al. Report by the ACNP Task Force on response and remission in major depressive disorder. Neuropsychopharmacology. 2006;31(9):1841-1853.

26. Cipriani A, Furukawa TA, Salanti G, et al. Comparative efficacy and acceptability of 12 new-generation antidepressants: a multipletreatments meta-analysis. Lancet. 2009;373(9665):746-758.

27. Keller MB. Remission versus response: the new gold standard of antidepressant care. J Clin Psychiatry. 2004;65(Suppl 4):53-59.

28. Hamilton M. A rating scale for depression. J Neurol Neurosurg Psychiatry. 1960;23:56-62.

29. Montgomery SA, Asberg M. A new depression scale designed to be sensitive to change. Br J Psychiatry. 1979;134:382-389.

30. Higgins JPT, Thompson SG, Deeks JJ, Altman DG. Measuring inconsistency in meta-analyses. BMJ. 2003;327(7414):557-560.

31. Riley RD, Higgins JP, Deeks JJ. Interpretation of random effects metaanalyses. BMJ. 2011;342:d549.

32. Egger M, Davey Smith G, Schneider M, Minder C. Bias in meta-analysis detected by a simple, graphical test. BMJ. 1997;315(7109):629-634.

33. Berman RM, Cappiello A, Anand A, et al. Antidepressant effects of ketamine in depressed patients. Biol Psychiatry. 2000;47(4): 351-354.

34. Murrough JW, Iosifescu DV, Chang LC, et al. Antidepressant efficacy of ketamine in treatment-resistant major depression: a twosite randomized controlled trial. Am J Psychiatry. 2013;170(10): 1134-1142.

35. Zarate CA Jr, Singh JB, Carlson PJ, et al. A randomized trial of an $\mathrm{N}$-methyl-D-aspartate antagonist in treatment-resistant major depression. Arch Gen Psychiatry. 2006;63(8):856-864.

36. Ghasemi M, Kazemi MH, Yoosefi A, et al. Rapid antidepressant effects of repeated doses of ketamine compared with electroconvulsive therapy in hospitalized patients with major depressive disorder. Psychiatry Res. 2014;215(2):355-361.

37. Lapidus KA, Levitch CF, Perez AM, et al. A randomized controlled trial of intranasal ketamine in major depressive disorder. Biol Psychiatry. 2014;76(12):970-976.

38. Hu C, Liu F, Wang X, Chen Y, Zhang T. The effects of ketamine on patients receiving general antidepression therapy. $J$ Clin Anesthesiol. 2014;30(9):848-850.

39. Sos P, Klirova M, Novak T, Kohutova B, Horacek J, Palenicek T. Relationship of ketamine's antidepressant and psychotomimetic effects in unipolar depression. Neuro Endocrinol Lett. 2013;34(4):287-293.

40. Deeks JJ, Altman DG, Bradburn MJ. Statistical methods for examining heterogeneity and combining results from several studies in metaanalysis. In: Systematic Reviews in Health Care: Meta-Analysis in Context, 2nd Ed. 2008:285-312.

41. Murrough JW, Burdick KE, Levitch CF, et al. Neurocognitive effects of ketamine and association with antidepressant response in individuals with treatment-resistant depression: a randomized controlled trial. Neuropsychopharmacology. 2015;40(5):1084-1090.

42. Salehi B, Mohammadbeigi A, Kamali AR, Taheri-Nejad MR, Moshiri I. Impact comparison of ketamine and sodium thiopental on anesthesia during electroconvulsive therapy in major depression patients with drugresistant; a double-blind randomized clinical trial. Ann Card Anaesth. 2015;18(4):486

43. Morgan CJ, Mofeez A, Brandner B, Bromley L, Curran HV. Acute effects of ketamine on memory systems and psychotic symptoms in healthy volunteers. Neuropsychopharmacology. 2004;29(1):208-218.

44. Morgan CJ, Muetzelfeldt L, Curran HV. Ketamine use, cognition and psychological wellbeing: a comparison of frequent, infrequent and ex-users with polydrug and non-using controls. Addiction. 2009; 104(1):77-87.

45. Edward Roberts R, Curran HV, Friston KJ, Morgan CJ. Abnormalities in white matter microstructure associated with chronic ketamine use. Neuropsychopharmacology. 2014;39(2):329-338. 
46. Murrough JW, Wan LB, Iacoviello B, et al. Neurocognitive effects of ketamine in treatment-resistant major depression: association with antidepressant response. Psychopharmacology. 2014;231(3):481-488.

47. Shiroma PR, Albott CS, Johns B, Thuras P, Wels J, Lim KO. Neurocognitive performance and serial intravenous subanesthetic ketamine in treatment-resistant depression. Int J Neuropsychopharmacol. 2014; 17(11):1805-1813.

48. Zanos P, Moaddel R, Morris PJ, et al. NMDAR inhibition-independent antidepressant actions of ketamine metabolites. Nature. 2016; 533(7604):481-486.
49. Tedesco V, Ravagnani C, Bertoglio D, Chiamulera C. Acute ketamineinduced neuroplasticity: ribosomal protein S6 phosphorylation expression in drug addiction-related rat brain areas. Neuroreport. 2013; 24(7):388-393.

50. Li N, Lee B, Liu R J, et al. mTOR-dependent synapse formation underlies the rapid antidepressant effects of NMDA antagonists. Science. 2010;329(5994):959-964.

51. Hayley S, Litteljohn D. Neuroplasticity and the next wave of antidepressant strategies. Front Cell Neurosci. 2013;7:218.

\section{Publish your work in this journal}

Neuropsychiatric Disease and Treatment is an international, peerreviewed journal of clinical therapeutics and pharmacology focusing on concise rapid reporting of clinical or pre-clinical studies on a range of neuropsychiatric and neurological disorders. This journal is indexed on PubMed Central, the 'PsycINFO' database and CAS, and is the official journal of The International Neuropsychiatric Association (INA). The manuscript management system is completely online and includes a very quick and fair peer-review system, which is all easy to use. Visit http://www.dovepress.com/testimonials.php to read real quotes from published authors.

Submit your manuscript here: http://www.dovepress.com/neuropsychiatric-disease-and-treatment-journal 